\title{
Atomic force microscopy and infrared spectroscopy studies of the thermal degradation of Nomex aramid fibres
} (Chemistry of Materials, 13, 4297-4304, 2001)

\author{
S. Villar-Rodil, J.I. Paredes, A. Martínez-Alonso, J.M.D. Tascón \\ Instituto Nacional del Carbón, CSIC, Apartado 73, 33080 Oviedo, Spain
}

In the present work, the thermal transformations of Nomex $[\operatorname{poly}(m$-phenylene isophthalamide)] fibres have been investigated up to a temperature of $1173 \mathrm{~K}$. The main stages of the pyrolytic degradation of the fibres were determined by thermal analysis and their chemical and morphological evolution through the different steps was subsequently followed by Fourier transform infrared spectroscopy (FTIR) and atomic force microscopy (AFM) measurements, respectively. The degradation starts with the cleaving of hydrogen bonds at approximately $633 \mathrm{~K}$, which leads to a disordering of the polyaramide chains on the nanometre scale. The next decomposition step takes place between 673 and $873 \mathrm{~K}$ with the disruption of the amide bonds, the subsequent breaking of the polyaramide chains into smaller units and their condensation into large polyaromatic compounds. From $873 \mathrm{~K}$ onwards, the reaction progresses by the dehydrogenation of the polyaromatic structures and their arrangement into graphite-like assemblies, resulting in the final fibrous carbon which is obtained at $1173 \mathrm{~K}$.

\section{Introduction}

Aramid fibres are a class of synthetic polymers which possess excellent thermal and oxidative stability, flame resistance and superior mechanical and dielectric behaviour. ${ }^{1}$ It is 
for these reasons that they have found increasing uses in a wide variety of demanding applications in modern technology. One of these applications takes advantage of their thermal stability and allows the manufacturing of heat-resistant materials for fire protection. ${ }^{2}$ In a different context, aramid fibres have been proposed in the last years as precusors of activated carbon materials with distinctive adsorbent properties, such as molecular sieve behaviour. ${ }^{3-5}$ The high crystallinity of this type of fibres is an important advantage for this purpose, which sets them apart from the usual fibrous precursors of low or intermediate crystallinity. In this case, the aramid fibres are normally transformed into activated carbon fibres by a two-step process: pyrolysis and (physical) activation. In consequence, the study of the thermal transformation of aramid fibres has relevance in order to, on one hand, understand the mechanisms by which the fibre degrades and, on the other hand, be able to select the most advantageous conditions to prepare activated carbon fibres.

The thermal degradation of aramid fibres has been investigated in the past through the analysis of the compounds evolved during their pyrolysis by such techniques as infrared spectroscopy, gas chromatography or mass spectrometry. ${ }^{6-11}$ These studies provided valuable indirect information on the chemistry of the degradation process of aramids. However, direct information on the changes undergone by the solid material upon pyrolysis is still lacking or is very rare. As a matter of fact, very few examples are reported in the literature ${ }^{8,11-14}$ and most of them concern Kevlar, poly( $p$-phenylene terephthalamide).

The main objective of this work was to get an insight into the chemical and morphological transformations undergone by the poly $(m$-phenylene isophthalamide) fibre known as Nomex, upon pyrolysis up to $1173 \mathrm{~K}$, when the polymer has been completely transformed into fibrous carbon. To date, the only direct available information about the thermal transformation of this polymer is essentially the elemental composition of the solid 
residue. $^{11,14}$ In the present work, Fourier transform infrared spectroscopy (FTIR) and atomic force microscopy (AFM) measurements have been carried out at different stages of the pyrolytic transformation of the fibre, selected by thermal analysis (TGA/DTG/DTA), to provide direct information about the changes taking place in the chemical bondings of the polymer (FTIR) and how those chemical changes affected the fibre surface morphology at the nanometre scale (AFM). The utility of FTIR to follow the thermal transformations of other polymeric materials during pyrolysis has been demonstrated in the past in a number of examples. ${ }^{15-18}$ On the contrary, the application of AFM to monitor the morphological changes induced by pyrolysis on a polymer at different steps of the process is much less common, though some related work can be found in the literature. ${ }^{19-22}$ Being an extremely surface-sensitive technique as it is (capable of atomic or molecular resolution in the most favourable cases) and having proved its capabilities for the study of a wide range of materials, ${ }^{23-27}$ AFM appears as a promising technique for this purpose. As will be shown thereafter, the morphological changes in the fibres during the different steps of pyrolysis are in general too subtle to be detected by more conventional microscopic techniques, such as scanning electron microscopy (SEM).

\section{Experimental}

The starting material employed was commercial poly( $m$-phenylene isophthalamide) fibre, known as Nomex ${ }^{\circledR}$, manufactured by DuPont. For the present study, a variety named Crystalline Nomex (Dtf 2.2) was used.

A Stanton-Redcroft STA-1500 thermobalance provided with a Plus-V software was used for simultaneous Thermogravimetry (TG) /Differential Thermal Analysis (DTA) measurements. The derivative of the TG curve (DTG) is also presented. As received fibres, 
without drying, were used in all the thermal treatments. Samples $(\sim 10 \mathrm{mg})$ were placed in Pt crucibles $5 \mathrm{~mm}$ in diameter and $5 \mathrm{~mm}$ in height. An argon (99.99990\% pure by volume) constant flow of $50 \mathrm{~cm}^{3} \mathrm{~min}^{-1}$ was used. Temperatures were measured with $\mathrm{Pt} / \mathrm{Rh}$ thermocouples placed at the bottom of the Pt crucibles, in contact with them. $\alpha$-Alumina was the reference material for DTA measurements. Several linear heating rates ranging from 5 to $40 \mathrm{~K} \mathrm{~min}^{-1}$ were tested over the temperature interval 298-1173 $\mathrm{K}$. Once a convenient heating rate was chosen, samples pyrolyzed to different selected temperatures were prepared in the same thermobalance under the same conditions, effectively stopping the process by rapid cooling to room temperature. These samples were considered to be representative of the different decomposition stages the material undergoes.

Elemental analyses of all samples were carried out in a LECO CHNS-932 microanalysis apparatus with a LECO VTF-900 accessory for oxygen. Fourier transform infrared (FTIR) absorption spectra were obtained in a Nicolet Magna IR560 spectrometer. Pellets in $\mathrm{KBr}$ with a sample concentration of 2 to $5 \times 10^{-1}$ wt \%, weighing $120 \mathrm{mg}$ and 13 $\mathrm{mm}$ in diameter, were used. The spectra shown are the result of coadding 200 interferograms obtained at a resolution of $4 \mathrm{~cm}^{-1}$ and normalized to $1 \mathrm{mg} \mathrm{cm}$. All samples, fresh and pyrolyzed, were cold-ground at $77 \mathrm{~K}$ in a mixer mill used in combination with a cooling attachment in which liquid nitrogen was the coolant. Then, they were kept in a desiccator, avoiding direct exposure to sunlight in order to prevent their photochemical degradation. ${ }^{28}$

Atomic force microscopy investigations of the different heat-treated samples were carried out in air at room temperature with a Nanoscope Multimode IIIa from Digital Instruments. In every case, bundles of the fibres were attached to the AFM sample holder by means of adhesive tape, taking special care to avoid the presence of fibres protruding a great length from the sample surface which could interfere with the cantilever and prevent 
from attaining stable imaging. The tapping mode of operation ${ }^{29,30}$ was chosen over the more conventional contact mode to follow the morphological evolution of the fibre with heat treatment temperature. This was due to the fact that the cantilevers employed in tapping mode (made of etched $\mathrm{Si}$, resonant frequency $\approx 250 \mathrm{kHz}$ ) have a considerably smaller tip radius of curvature $(5-10 \mathrm{~nm})$ than those used for contact mode and also that the lateral shear forces in the former mode are greatly reduced as compared with those of the latter, resulting in a better resolution of nanometre-sized features. ${ }^{31}$ Particular attention was paid to minimize the tip-sample interaction during the tapping mode AFM measurements, this being necessary in order to obtain accurate surface topographic information. ${ }^{32}$ To confirm the reproducibility of the images, several different previously unused tips were employed to study the samples and every sample was imaged on many different fibers and every fiber on several different areas. All the images shown here were flattened and then smoothed by a low-pass filter to improve their visual presentation, taking special care to ensure that no artifacts or distortions were introduced by this procedure.

\section{Results}

\subsection{Determination of the main stages of pyrolysis: Thermal analysis studies}

Figs. 1 and 2 show some of the TG and DTA curves, respectively, obtained by varying the heating rate in the pyrolysis process. Apparently, changing this parameter does not modify the mechanism of pyrolysis: the TG curves keep their shape and simply shift to higher temperatures with increasing heating rates, resulting in higher yields, and all the

DTA curves show the same features. Therefore, an intermediate heating rate of $10 \mathrm{~K} \mathrm{~min}^{-1}$ was chosen (Figs. $1 \mathrm{~b}$ and $2 \mathrm{~b}$ ) for the subsequent experiments. 


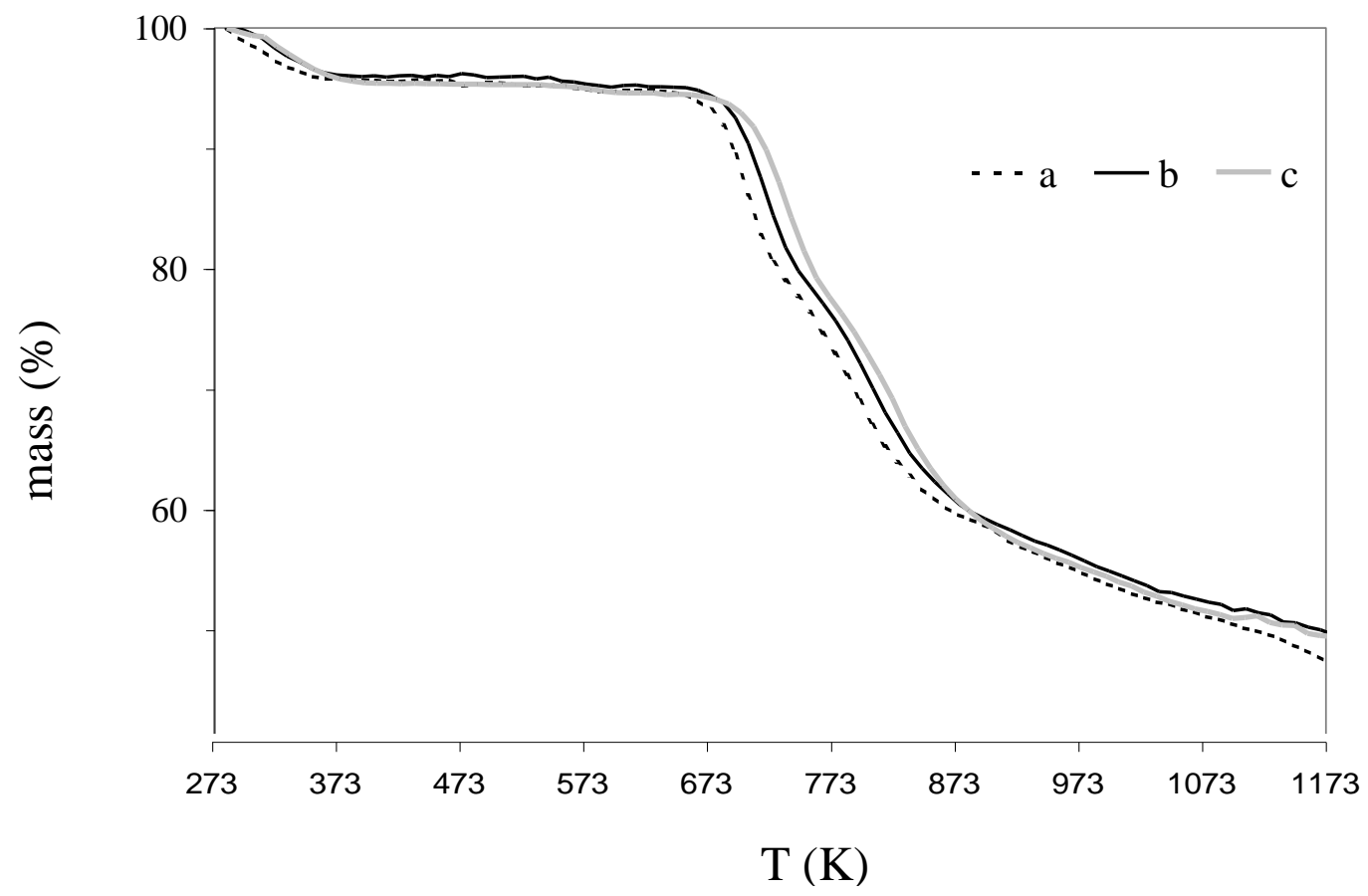

Figure 1. TG curves for heat treatments of Nomex under argon atmosphere using heating rates of 5 (a), 10 (b) and $20 \mathrm{~K} \mathrm{~min}^{-1}$ (c).

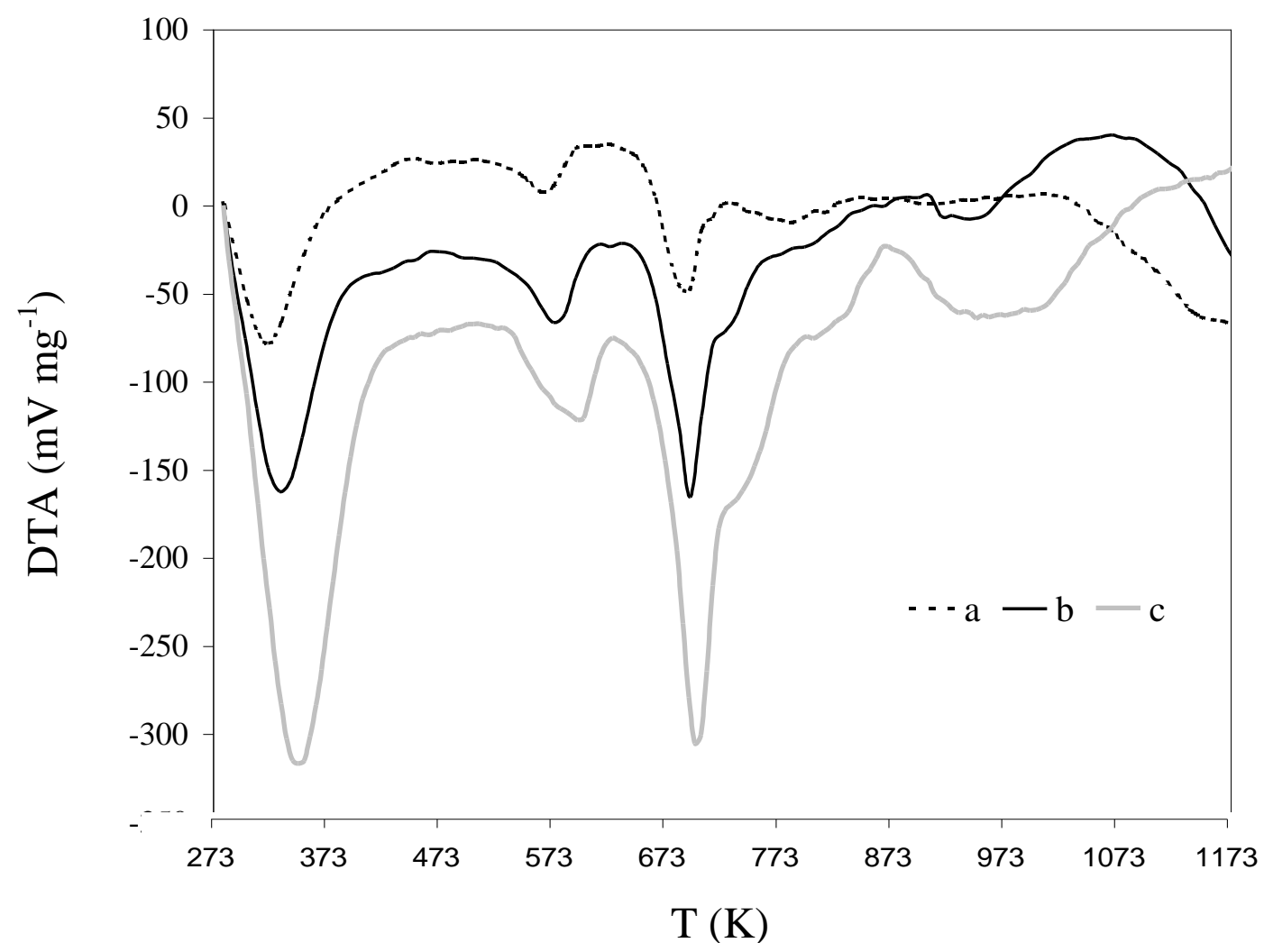

Figure 2. DTA curves for heat treatments of Nomex under argon atmosphere using heating rates of 5 (a), $10(\mathrm{~b})$ and $20 \mathrm{~K} \mathrm{~min}^{-1}$ (c). 


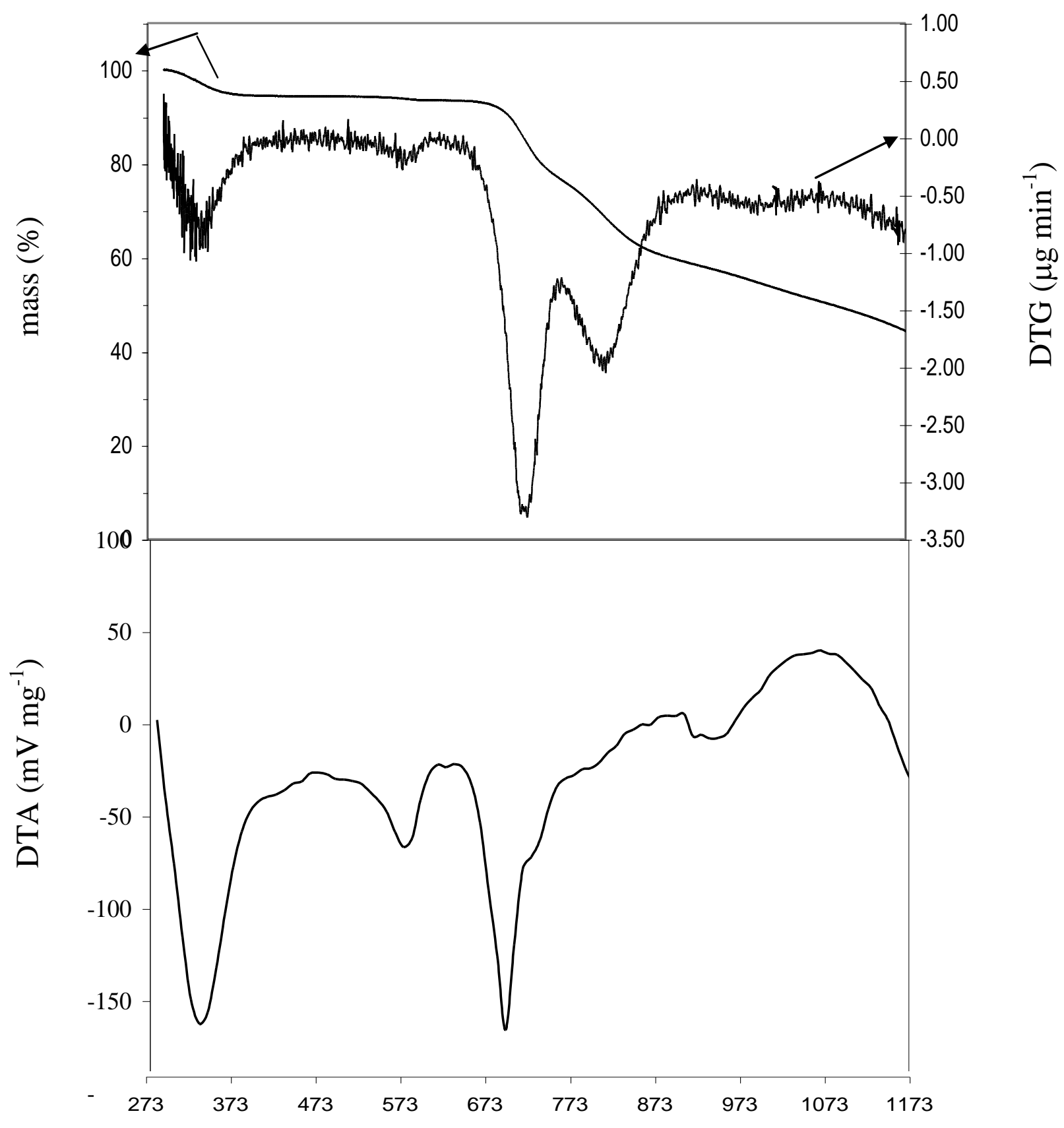

$\mathrm{T}(\mathrm{K})$

Figure 3. TG, DTG and DTA curves for Nomex pyrolysis under argon with a heating rate of $10 \mathrm{~K} \mathrm{~min}^{-1}$. 
TG (together with its derivative vs. temperature, DTG) and DTA curves obtained during Nomex pyrolysis under argon with a heating rate of $10 \mathrm{~K} \mathrm{~min}^{-1}$ are shown in Fig. 3. The first mass loss observed in the TG curve, which spans from room temperature to 378 $\mathrm{K}$ and is accompanied by an endothermal effect in the DTA curve with minimum at $333 \mathrm{~K}$, is ascribable to release of adsorbed moisture. No further changes occur until $543 \mathrm{~K}$. The transformation undergone by the sample at this temperature is barely noticeable by a mass loss of approximately $1 \% \mathrm{wt}$. recorded in the TG curve but it is highlighted in the DTG curve and also appreciated as an endothermal DTA peak with minimum centred at $590 \mathrm{~K}$.

The major mass loss starts at approximately $673 \mathrm{~K}$. Two steps are observed in the TG curve in the temperature ranges $673-753 \mathrm{~K}$ and $753-873 \mathrm{~K}$. As regards DTA results, there is a well-defined endothermal peak with minimum at $700 \mathrm{~K}$, located in the middle of the first mass loss step. However, peaks are not well-defined in the temperature range corresponding to the second TG step, suggesting that endothermal and exothermal effects are superimposed. From $873 \mathrm{~K}$ on, the TG curve shows a small but continuous mass loss which persists even at $1173 \mathrm{~K}$, accompanied by an exothermal effect in the DTA curve.

The samples studied by FTIR and AFM were chosen and prepared to be representative of the different stages of pyrolysis as evidenced by the thermal analysis results.

3.2 Chemical evolution during pyrolysis: Elemental analysis and infrared spectroscopy measurements

The analysed elements $(\mathrm{C}, \mathrm{H}, \mathrm{O}, \mathrm{N})$ sum 100 wt. \% within the experimental error. Thus, the starting material does not contain inorganic impurities in detectable quantity. This is confirmed by the fact that Nomex leaves no residue neither after high temperature 
oxidation in air nor after low temperature oxidation in a oxygen plasma. There is no significant change in the elemental composition of the sample until $823 \mathrm{~K}$. From then onwards, the sample gradually increases its content of $\mathrm{C}$, as expected in any carbonization process, while its atomic percentage of hydrogen decreases. The other heteroatoms, nitrogen and oxygen, are retained to a great extent. As a matter of fact, their atomic percent varies little during the whole process (Table 1).

Table 1. Chemical analyses of Nomex, fresh and decomposed at various temperatures.

\begin{tabular}{|c|c|c|c|c|c|c|c|c|}
\hline $\begin{array}{c}\mathrm{T} \\
(\mathrm{K})\end{array}$ & $\begin{array}{c}\mathrm{C} \\
(\text { wt } \%)\end{array}$ & $\begin{array}{c}\mathrm{H} \\
(\mathrm{wt} \%)\end{array}$ & $\begin{array}{c}\mathrm{O} \\
(\mathrm{wt} \%)\end{array}$ & $\begin{array}{c}\mathrm{N} \\
(\mathrm{wt} \%)\end{array}$ & $\begin{array}{c}\mathrm{C} \\
(\text { atomic \%) }\end{array}$ & $\begin{array}{c}\mathrm{H} \\
(\text { atomic } \%)\end{array}$ & $\begin{array}{c}\mathrm{O} \\
(\text { atomic } \%)\end{array}$ & $\begin{array}{c}\mathrm{N} \\
\text { (atomic \%) }\end{array}$ \\
\hline 293 & 71.2 & 3.9 & 15.6 & 9.7 & 51.6 & 33.9 & 8.4 & 6.0 \\
\hline 473 & 69.7 & 4.7 & 16.2 & 9.5 & 47.7 & 38.5 & 8.3 & 5.6 \\
\hline 633 & 69.8 & 4.1 & 15.7 & 9.6 & 50.2 & 35.4 & 8.5 & 5.9 \\
\hline 706 & 71.9 & 4.0 & 13.7 & 9.8 & 52.1 & 34.3 & 7.5 & 6.1 \\
\hline 725 & 69.5 & 4.1 & 13.9 & 9.5 & 50.8 & 35.6 & 7.6 & 6.0 \\
\hline 773 & 73.9 & 3.8 & 10.7 & 10.0 & 54.3 & 33.5 & 5.9 & 6.3 \\
\hline 823 & 76.5 & 4.1 & 6.3 & 10.2 & 53.0 & 35.3 & 3.4 & 6.3 \\
\hline 858 & 78.4 & 3.6 & 5.1 & 10.0 & 58.6 & 32.2 & 2.9 & 6.4 \\
\hline 923 & 79.8 & 3.5 & 5.8 & 9.0 & 60.0 & 30.9 & 3.3 & 5.8 \\
\hline 1023 & 80.4 & 2.2 & 7.4 & 7.0 & 67.8 & 22.4 & 4.7 & 5.1 \\
\hline 1173 & 83.6 & 1.4 & 8.0 & 6.7 & 74.5 & 15.1 & 5.4 & 5.1 \\
\hline
\end{tabular}

The FTIR spectrum of fresh Nomex can be seen in Fig. 4a and the main band assignments made in it are shown in Table 2. The spectra of samples treated at temperatures 633 through $1173 \mathrm{~K}$ are shown in Fig. 4b-1. The spectrum of the sample heated to $633 \mathrm{~K}$ is virtually the same as that of the fresh sample except for a slight shift ( $10 \mathrm{~cm}^{-1}$ ) to higher wavenumbers of the $\mathrm{N}-\mathrm{H}$ stretching absorption band. As already mentioned, there is no remarkable change in the elemental composition of the sample until $823 \mathrm{~K}$ (Table 1) and so the number and position of the bands remain invariable through thermal treatments up to that temperature. The only exception is the appearance of an aryl nitrile band $\left(2230 \mathrm{~cm}^{-1}\right)$ at $746 \mathrm{~K}$. Consequently, it is possible to establish comparisons of 


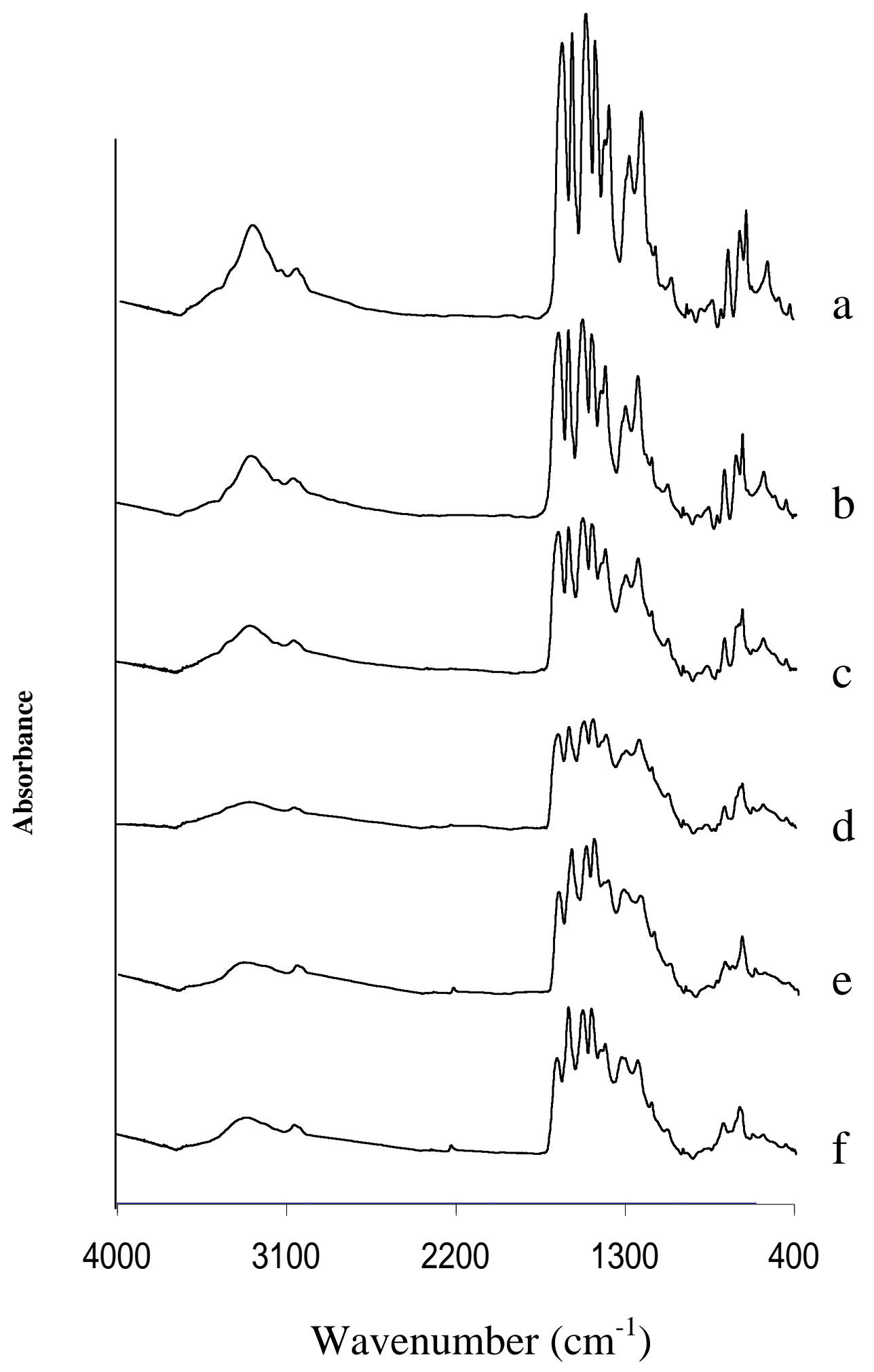




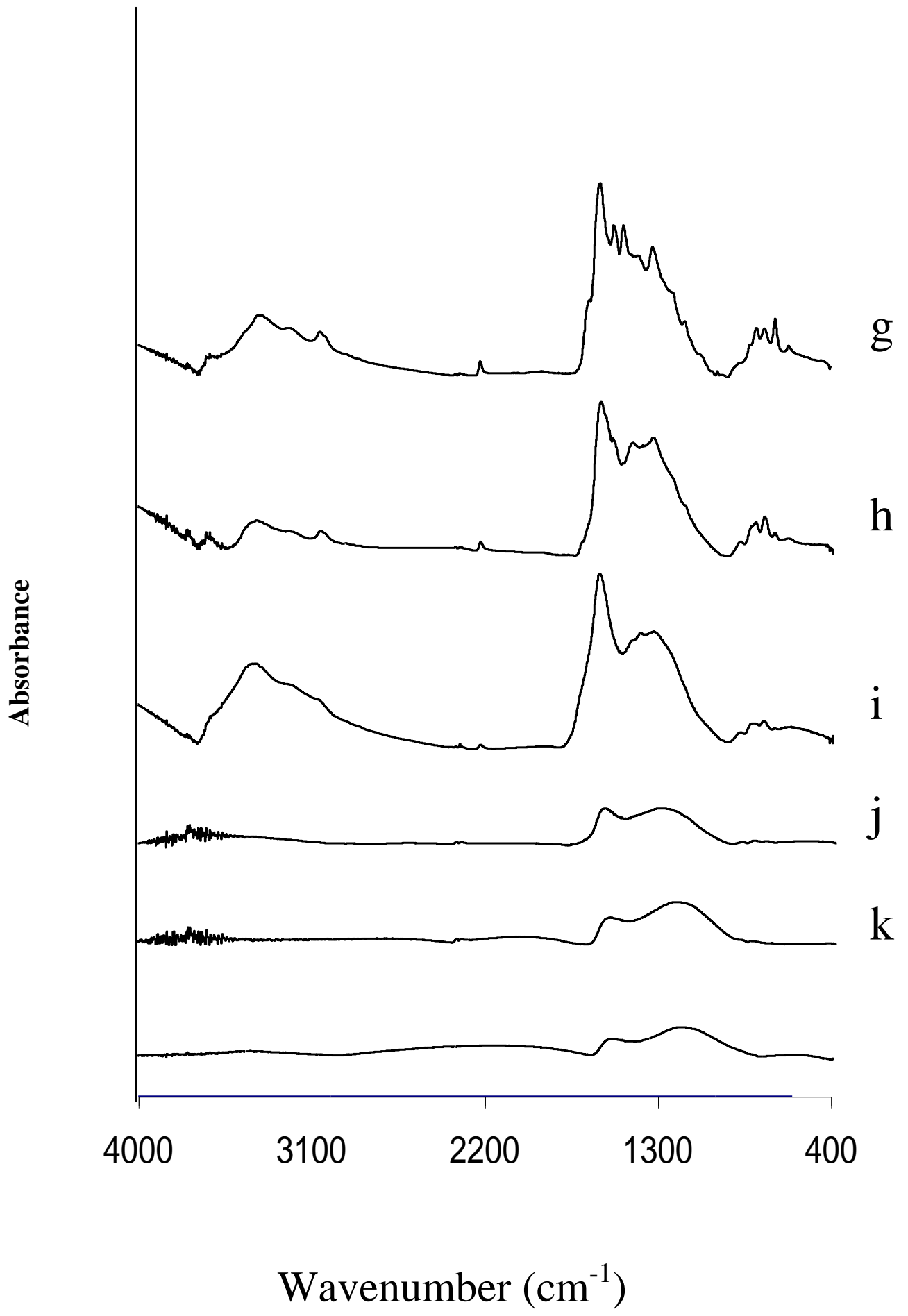

Figure 4. FTIR spectra of fresh Nomex (a) and its solid decomposition products at 633 (b), 706 (c), 746 (d), 803 (e) 823 (f), 873 (g), 923 (h), 973 (i), 1023 (j), 1073 (k) and 1173 K (1). 
peak intensities between the spectra of the fresh material and the samples in the 633-823 K temperature range. These comparisons are given in Table 3.

Table 2. FTIR band assignments in fresh Nomex.

\begin{tabular}{|c|c|}
\hline $\begin{array}{l}\text { Wavenumber } \\
\left(\mathrm{cm}^{-1}\right)\end{array}$ & Band assignments \\
\hline 3300 & $\begin{array}{l}\text { N-H stretching vibrations in a secondary amide in trans form with a bonded } \\
\text { hydrogen }\end{array}$ \\
\hline 3065 & C-H stretching vibrations in an unsaturated compound \\
\hline 1660 & $\begin{array}{l}\text { amide } \mathrm{C}=\mathrm{O} \text { stretching (usually designated as amide } \mathrm{I} \text { band) for hydrogen-bonded } \\
\text { amide groups }\end{array}$ \\
\hline 1608 & $\mathrm{C}=\mathrm{C}$ stretching vibrations of aromatic ring \\
\hline 1536 & $\begin{array}{l}\mathrm{N}-\mathrm{H} \text { in plane bending and C-N stretching coupled modes of the C-N-H group (also } \\
\text { known as amide II band) }\end{array}$ \\
\hline 1305 & aromatic C-N stretching \\
\hline 1240 & C-N stretching, N-H in plane bending, $\mathrm{C}-\mathrm{C}$ stretching (amide III) \\
\hline 781,685 & $\begin{array}{l}\text { out-of-plane C-H vibrations of one and three adjacent hydrogens in a meta- } \\
\text { substituted aromatic ring }\end{array}$ \\
\hline 720 & N-H out-of-plane bending (amide V) \\
\hline
\end{tabular}

Table 3. FTIR band intensity ratios at various decomposition temperatures.

\begin{tabular}{cccc}
\hline $\mathrm{T}$ & $1660 \mathrm{~cm}^{-1} /$ & $1608 \mathrm{~cm}^{-1} /$ & $1608 \mathrm{~cm}^{-1} /$ \\
$(\mathrm{K})$ & $3300 \mathrm{~cm}^{-1}$ & $3065 \mathrm{~cm}^{-1}$ & $1660 \mathrm{~cm}^{-1}$ \\
\hline 293 & 3.05 & 6.03 & 1.03 \\
706 & 3.06 & 4.60 & 1.01 \\
746 & 3.64 & 5.11 & 1.08 \\
803 & 3.53 & 5.72 & 1.43 \\
823 & 2.93 & 5.78 & 1.54 \\
\hline
\end{tabular}

The first column shows the ratio between the intensities of the amide $\mathrm{C}=\mathrm{O}$ absorption band and the amide $\mathrm{N}-\mathrm{H}$ band. As both bands correspond to the same chemical group, the quotient remains nearly constant through all the process. The second column corresponds to the ratio between absorption intensities for the aromatic $\mathrm{C}=\mathrm{C}$ band and the $\mathrm{C}-\mathrm{H}$ band for the polymer. Again, this quotient remains reasonably constant in the mentioned temperature range. The third column gives the relative intensity between the bands corresponding to the aromatic $\mathrm{C}=\mathrm{C}$ bonds and the amide $\mathrm{C}=\mathrm{O}$ bonds, which remains constant up to temperatures of $746 \mathrm{~K}$ and increases at higher temperatures. Regarding the 
aryl nitrile, an increase in the intensity of its corresponding band is observed in the course of the degradation, as can be appreciated in Fig. 4.

As the changes in the FTIR spectra at temperatures higher than $823 \mathrm{~K}$ are so great that the initial bands are severely altered, there is no point in making quantitative comparisons with the preceding spectra. In consequence, results for these samples do not appear in Table 3. Above $873 \mathrm{~K}$ (Fig. 4g), all the bands ascribed to the amide group disappear completely. In contrast, the peak centred at $1608 \mathrm{~cm}^{-1}$, related to the aromatic bonds, persists and even broadens with increasing heat treatment temperature. The only FTIR spectrum of pyrolyzed Nomex found in the literature ${ }^{8}$ corresponds to a sample heattreated at $823 \mathrm{~K}$ for 15 minutes and is consistent with the spectra shown here, it being halfway between those corresponding to 823 and $873 \mathrm{~K}$ (Figs. 4f and 4g). At $1023 \mathrm{~K}$ (Fig. 4j) the aryl nitrile band has vanished as a consequence of the decomposition of this previously formed product. As indicated by the elemental analysis (Table 1), between 923 and $1023 \mathrm{~K}$ the atomic content of hydrogen significantly diminishes and this fact is reflected in the drop in intensity of the $\mathrm{N}-\mathrm{H}$ and $\mathrm{C}-\mathrm{H}$ stretching bands in the related spectra shown in Fig. 4. Finally, at $1173 \mathrm{~K}$ (Fig. 4l), the FTIR spectrum of the sample shows the typical absence of absorption bands of many carbonaceous materials.

\subsection{Morphological evolution during pyrolysis: Atomic force microscopy imaging}

Before showing the AFM results for the different heat-treated samples, it is interesting to present some SEM images for comparison. These were obtained using a Zeiss DSM-942 apparatus with samples gold coated for electron conduction. Fig. 5 shows typical SEM micrographs of the fresh Nomex fibre (a) and the fibre pyrolysed at $1173 \mathrm{~K}$ (b). Both samples exhibit striations more or less parallel to the fibre axis, being apparently 
somewhat deeper and more numerous in the former case, which may indicate a general smoothing upon fibre degradation. Apart from this difference and from the fact that, as expected, a decrease in the diameter of the final pyrolysed fibre as compared to that of the starting fibre $(\sim 16 \mu \mathrm{m}$ vs. $20 \mu \mathrm{m})$ is observed (arising from the consumption of a considerable portion of material at $1173 \mathrm{~K}$ ), detailed morphological differences between the two fibres could not be detected at the magnifications that can be attained by SEM, and the same applied for the other heat-treated samples. If the fibres experience nanometrescale morphological changes upon the different steps of pyrolysis, they would only be clearly detected by AFM.

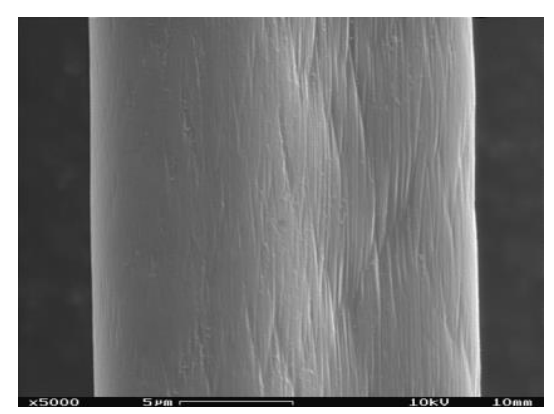

a

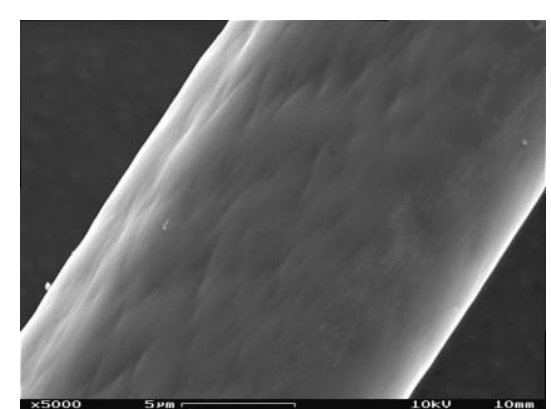

$\mathrm{b}$

Figure 5. SEM micrographs of the Nomex fibres before and after pyrolysis. (a) Fresh fibre. (b) Final pyrolysed fibre (1173 K). 

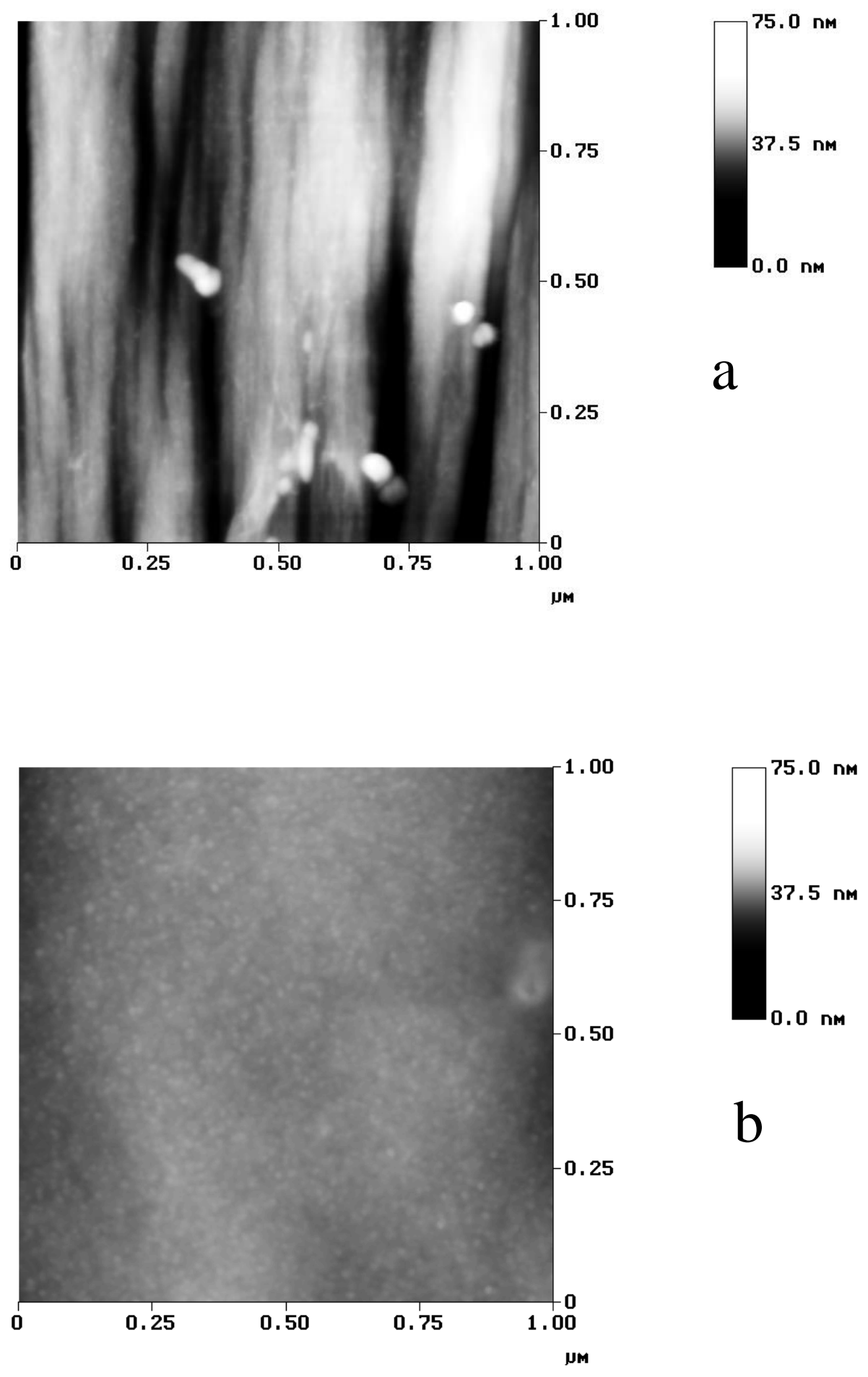

Figure 6. General appearance of Nomex fibre before and after pyrolysis. The images were obtained by tapping mode AFM. (a) Fresh fibre. (b) Fibre pyrolysed at 1173 K. Lateral size: $1 \mu \mathrm{m}$. 
Fig. 6 presents some AFM images comparing the general appearance of the same samples as in Fig. 5. As can be seen, the difference between the starting material and the final carbonized fibre now becomes readily obvious. The former presents a morphology consisting of fibrils parallel to the fibre axis (from top to bottom in all the images presented here). These fibrils have typical diameters of a few tens of $\mathrm{nm}$ and are more or less arranged into groups separated by striations $50-100 \mathrm{~nm}$ wide and 20-30 nm deep. Most probably, some of the striations are those observed also by SEM (Fig. 5a). By contrast, the fibrillar morphology has completely disappeared from the sample heat-treated at $1173 \mathrm{~K}$. Now the topography turns out to be much smoother (RMS roughness values of 1-3 nm, compared to 7-10 nm for the untreated fibre), as also evidenced in the line profiles of Fig. 7, and is characterized by approximately rounded platelets (which will be shown in more detail subsequently) typically between 10 and $20 \mathrm{~nm}$ in diameter. No preferred orientation of the features along the fibre axis can be evidenced now, in contrast to the fresh Nomex fibre. In consequence, the fibre surface has become more isotropic after the pyrolytic transformation.

In Fig. 8, the detailed nanometre-scale evolution of the fibre surface morphology with heat treatment for selected temperatures, as detected by AFM, is shown. Although slight variations in the exact morphology could sometimes be observed from place to place within a given sample, the general features outlined in the images of Fig. 8 were found to be representative of the changes undergone by the fibres upon heat treatment, since they reflected trends observed with a high reproducibility everywhere. As can be appreciated, there is a gradual transformation of the starting Nomex fibre (a) into the final fibrous carbon (f). Initially, as mentioned previously, the Nomex fibre presents a structure made up of long fibrils approximately parallel to the fibre axis (a reflection of its molecular 

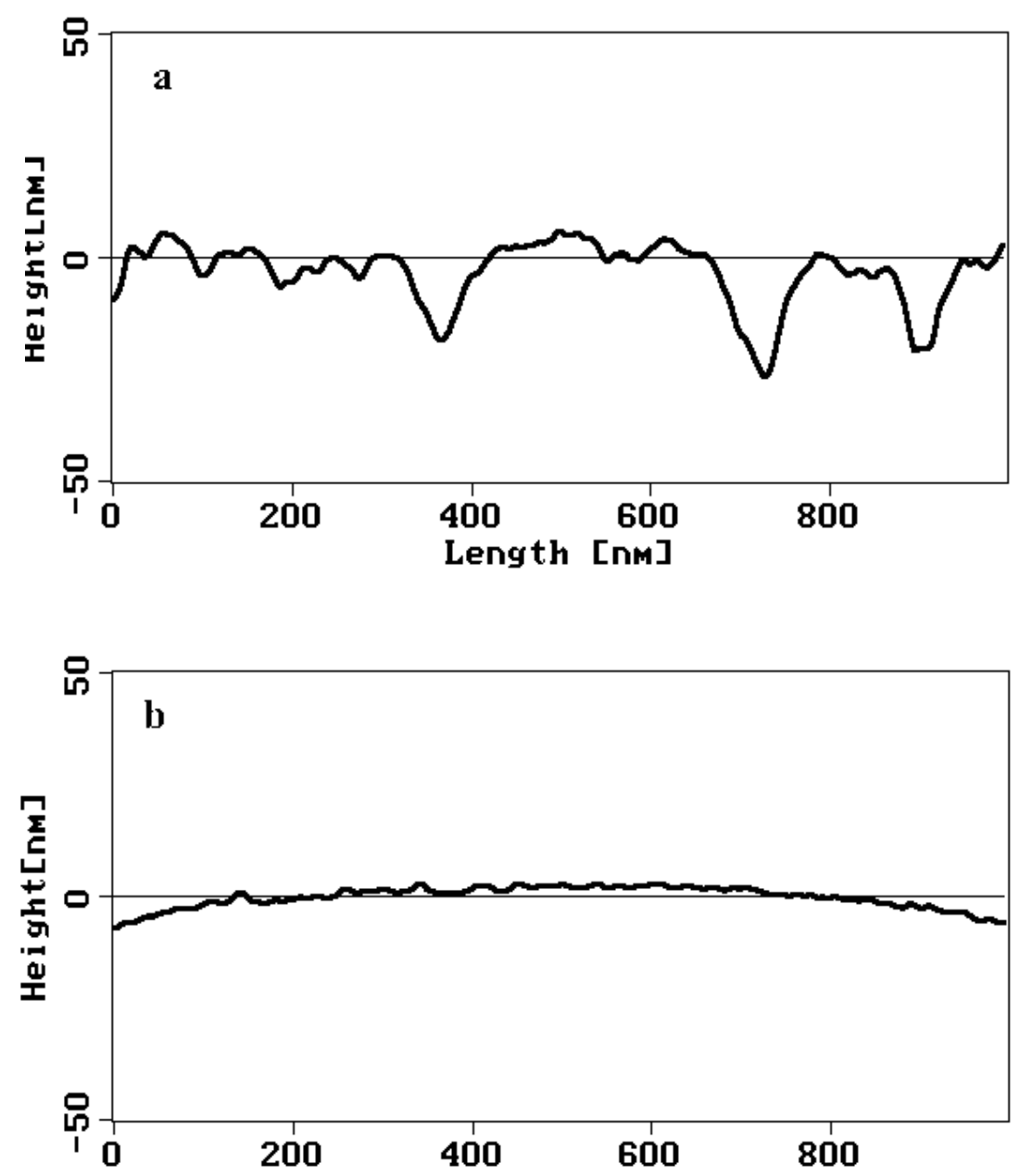

Figure 7. Line profiles of the fresh and pyrolysed fibres from the images of Fig. 6. (a) Fresh fibre. (b) Fibre pyrolysed at $1173 \mathrm{~K}$. The line profiles are drawn from left to right in the images, that is, perpendicularly to the fibre axis. 
Figure 8. AFM images of the surface morphological evolution of fresh Nomex (a) and its solid decomposition products at 633 (b), 706 (c), 736 (d), 823 (e) and $1173 \mathrm{~K}$ (f). Lateral size: $250 \mathrm{~nm}$
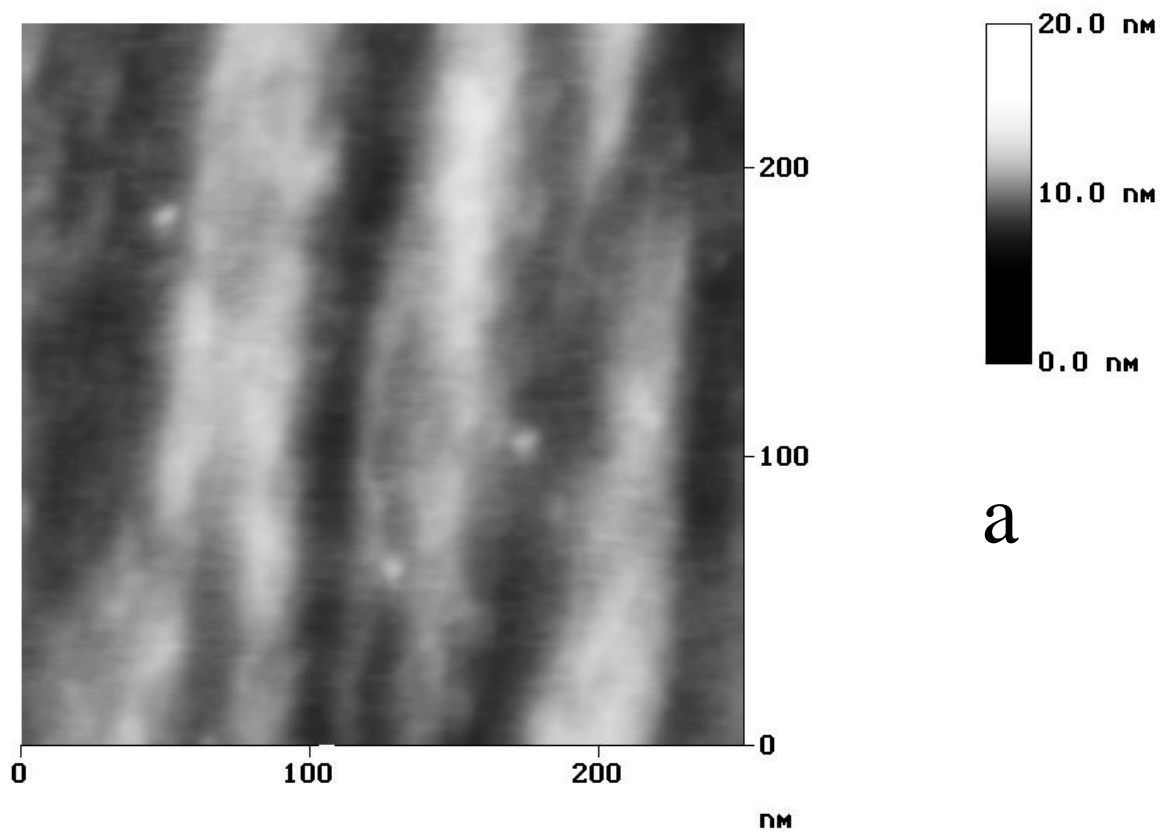

a
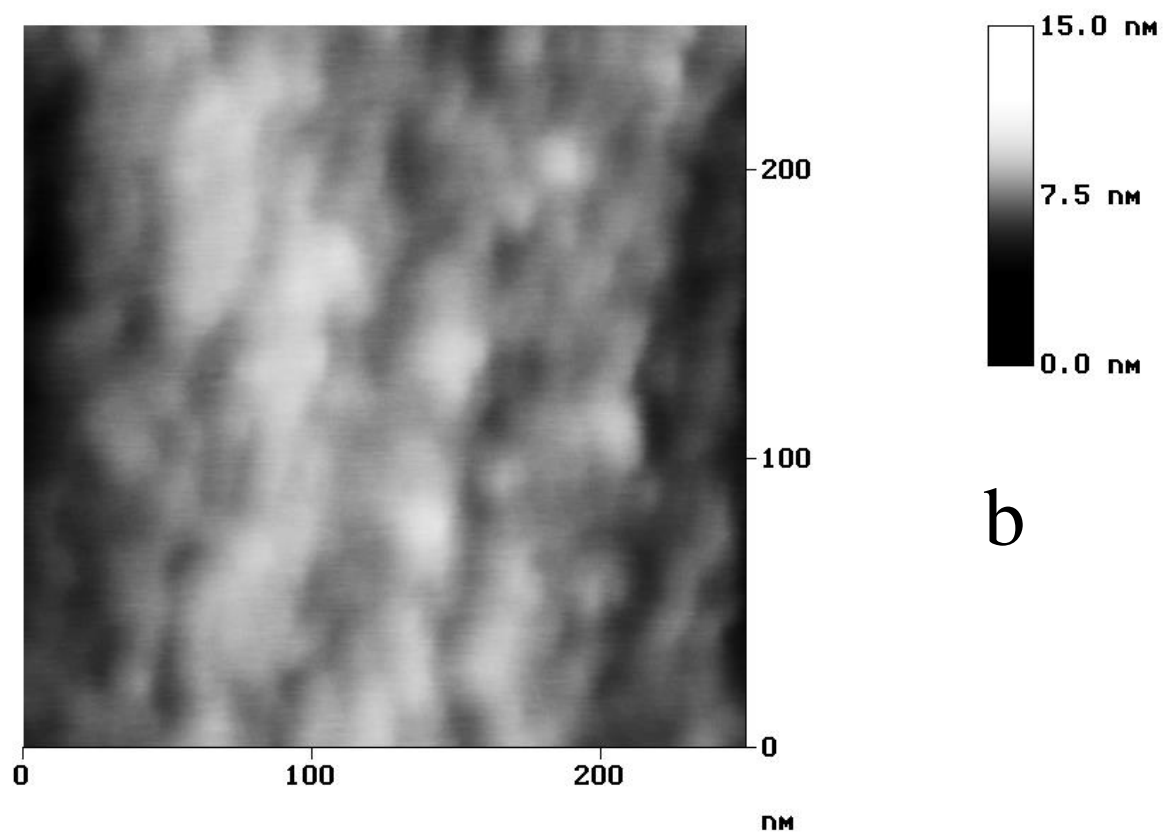

b 

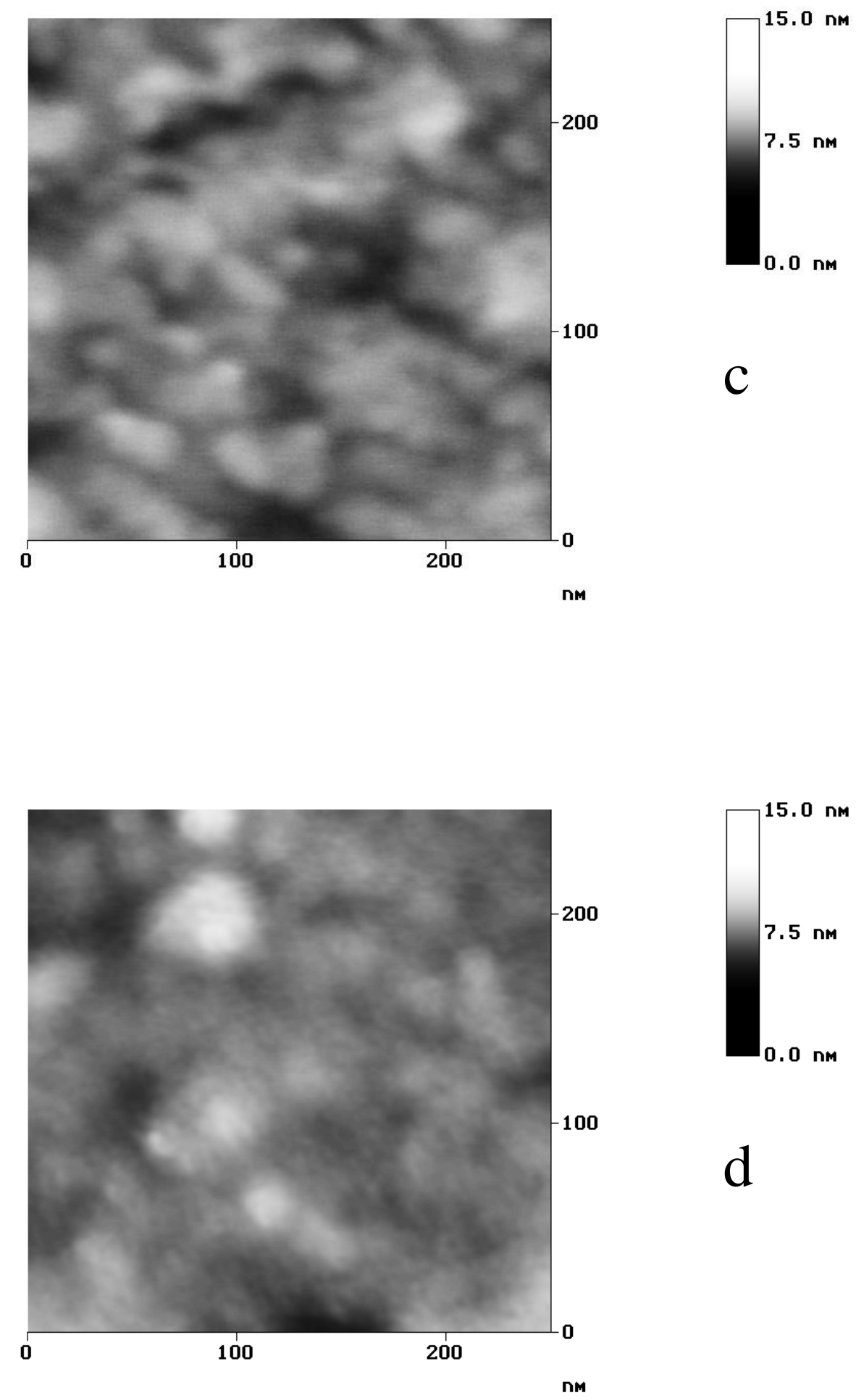

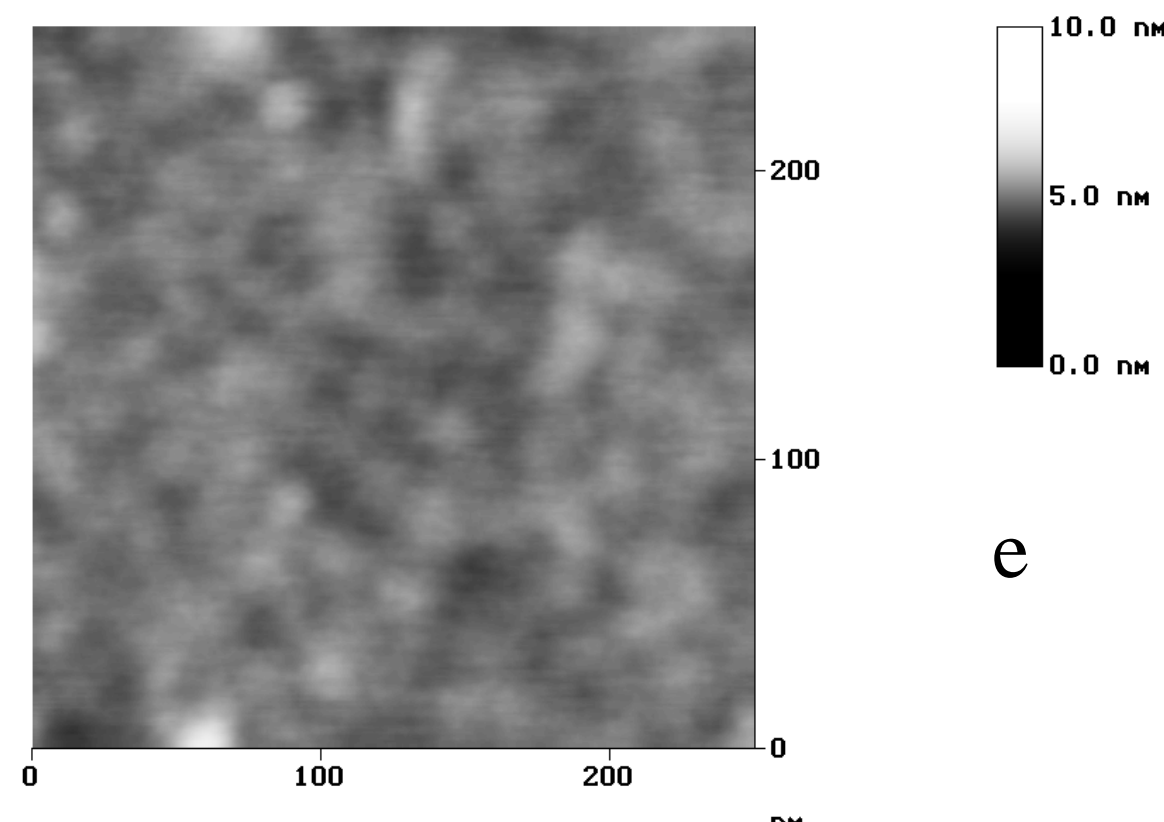

e
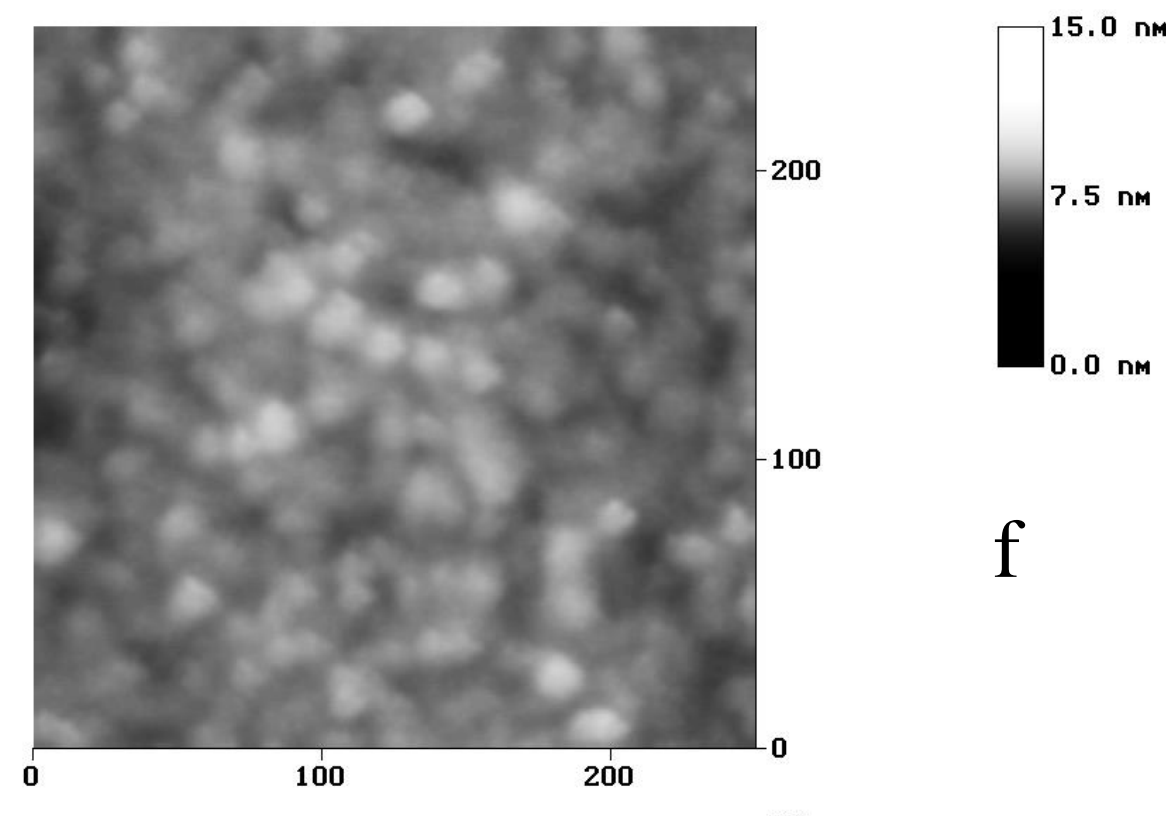

f

nM 
morphology are observed. After a heat treatment of $633 \mathrm{~K}(\mathrm{~b})$, the anisotropy characteristic of the starting material has been lost to a noticeable extent and the long fibrils of the fresh fibre have been replaced by shorter features, as if the fibrils were truncated at several points, losing their long range (along the fibre axis) cohesiveness. Upon pyrolysis at $706 \mathrm{~K}$ (c), the anisotropy of the fibre has disappeared completely and its morphology consists of more or less rounded or elongated features with typical lateral sizes around $20 \mathrm{~nm}$ arranged in a disorganized way. Increasing the heat treatment temperature by $30 \mathrm{~K}$, up to $736 \mathrm{~K}$ (d), results in a smoothing of the surface topography but the general features are quite similar to those of the previous sample, only perhaps they are now more rounded. After a heat treatment of $823 \mathrm{~K}(\mathrm{e})$, the fibre surface appears highly isotropic and comprised of rounded domains (platelets) with diameters between 10 and $20 \mathrm{~nm}$. This turns out to be, in essence, the final morphology of the pyrolysed material, since no fundamental changes in the surface features take place by raising the heat treatment temperature to $1173 \mathrm{~K}$ (f), after which the aramid fibre has been thoroughly converted into fibrous carbon. The only difference observed is that in the final pyrolysed sample the features are somewhat more pronounced in the $\mathrm{z}$ direction than in the $823 \mathrm{~K}$ sample, but basically, from a morphological point of view, the final carbonised material is already developed at this latter temperature.

It should also be noted that in the particular case of the $1173 \mathrm{~K}$ sample, further evidence of its morphology could be obtained from scanning tunneling microscopy (STM). The images recorded by STM were totally consistent with those acquired by AFM: rounded nanometre-sized features and absence of directionality along the fibre axis. For the rest of the samples, and due to a lack of conductivity, STM imaging was not practicable because the tip would crash onto the samples. 


\section{Discussion}

From the results presented in this work, several observations regarding the mechanisms of the thermal transformation of the Nomex fibre into fibrous carbon can be made. The first step in the process of the thermal degradation takes place at about $633 \mathrm{~K}$ with the cleavage of the hydrogen bonds that hold the polyaramide chains together. This breaking of the hydrogen bonds in Nomex is reflected in the endothermal effect registered in its DTA curve, and also in the small mass loss $(\sim 1 \%)$ recorded in the TGA curve (Fig. 3) due to release of water present in the crystalline lattice, ${ }^{9}$ which was most probably forming hydrogen bonds with the amide groups. Evidence for the cleavage of the hydrogen bonds is also found in the FTIR spectra (Fig. 4b): the shifting of the $\mathrm{N}-\mathrm{H}$ amide band observed at $633 \mathrm{~K}\left(\sim 10 \mathrm{~cm}^{-1}\right)$ is characteristic of the breaking of this type of bond. ${ }^{33}$ The AFM images at this temperature (Fig. 8b) also reflect this change: as mentioned previously, the long fibrils typical of the pristine material have been replaced to a considerable extent by shorter features, without long range cohesiveness. This can be explained by the rupture of the hydrogen bonds, which leaves the polyaramide chains free to rearrange, so that they curl up in a disorganized way when the sample is allowed to cool down to room temperature. As a result, the chains lose their originally stretched arrangement and the anisotropy of the starting material is reduced.

The rupture of hydrogen bonds between polymer chains occurs prior to the main mass loss and is well differentiated from the onset of this process, which starts at $673 \mathrm{~K}$ and continues up to $873 \mathrm{~K}$. In this range of temperatures, the second step in the polymer decomposition comes about. Now, the amide bonds which hold the aromatic units together begin to break down and, as a consequence, the polyaramide chain collapses and divides into shorter chains. The TG results (Fig. 3) evidence the existence of two regimes for this 
step, as commented beforehand. The first one, between 673 and $753 \mathrm{~K}$, reflects the heterolytic breaking of the amide bonds. ${ }^{7,9}$ This is also noticed in the DTA curve (Fig. 3), which shows an endothermal peak at $700 \mathrm{~K}$. The second regime spreads between 753 and $873 \mathrm{~K}$ and arises from the homolytic rupture of the amide bonds. The FTIR results corroborate the splitting of this step into two regimes: while the intensities of the bands related to the amide group and the aromatic ring drop in parallel in the first regime, in the second only the intensities of the former diminish (Table 3). This observation suggests the occurrence of both polycondensation reactions, which are exothermal processes, and homolytic ruptures of the amide bonds (endothermal) simultaneously, which leads to the superposition of the two effects in the DTA curve in the temperature range between 753 and $873 \mathrm{~K}$. The polycondensation reactions give rise to an increasing aromatization of the heat-treated sample. As regards the products of the rupture of the amide bond, aryl nitrile compounds have been detected in the present work $\left(2230 \mathrm{~cm}^{-1}\right.$ band in the FTIR spectra, Fig. 4) and also in previous studies. ${ }^{10,13}$ Concerning the AFM results, the breaking of the polyaramide chains into smaller units and the subsequent disorder this effect brings about is reflected in a further reduction of anisotropy in the sample surface morphology (Figs. 8c through e).

Polycondensation reactions continue after $873 \mathrm{~K}$, when amide bonds have disappeared (Fig. 4h). The polycondensation is reflected in the small but continuous mass loss observed in the TG curve for this temperature range, coincident with a DTA (Fig. 3) exothermal effect and the decrease in the hydrogen content (Table 1). It is also manifested by the persistence of a broadened peak at $1608 \mathrm{~cm}^{-1}$ in the FTIR spectra corresponding to the aromatic absorption band. The AFM morphology shown here at a temperature of 1173 $\mathrm{K}$ has also been found for other disordered carbonized materials, ${ }^{34}$ and is made up of small stacks $\left(\sim 6 \mathrm{~nm}^{35}\right)$ of graphite-like layers. Finally, the relative similarity in morphology 
between the AFM images of the samples heat-treated at $823 \mathrm{~K}$ and $1173 \mathrm{~K}$ should be drawn to attention: it strongly suggests a considerable aromatization of the former sample, in agreement with the DTA and FTIR observations. Thus, the general picture at this last stage of the degradation process is that the skeleton of the final carbonaceous material has already been developed to a considerable extent at $823 \mathrm{~K}$ and, essentially, the evolution of the fibre from that temperature up to the formation of the final fibrous carbon at $1173 \mathrm{~K}$ proceeds by the dehydrogenation of the aromatic structures to eventually form small graphite-like assemblies.

\section{Conclusions}

FTIR and AFM have proved to be very valuable techniques for providing direct and complementary information on the thermal degradation of Nomex aramid fibres. The chemical and morphological changes observed by these two techniques were found to be consistent with each other: a) The rupture of hydrogen bonds between polyaramide chains revealed by FTIR was also evidenced by an increasing disorganization and a noticeable reduction of anisotropy observed in the AFM images on the nanometre scale. b) The disruption of the amide bonds which the FTIR spectra indicated, and the subsequent splitting of the chains into smaller units, led to a further reduction of anisotropy and increasing nanometre-scale morphological disorder, as AFM was able to show. c) The early $(823 \mathrm{~K})$ signs of polycondensation reactions appearing in the FTIR spectra and the dehydrogenation which follows at higher temperatures were coherent with the similarity between AFM images at $823 \mathrm{~K}$ and higher temperatures, this resemblance strongly

suggesting the formation of polyaromatic compounds at the former temperature. The 
morphological changes detected by AFM upon the different stages of pyrolysis could also reveal helpful in similar studies of thermal treatment/degradation of other polymers.

\section{Acknowledgements}

The authors wish to thank their colleagues Javier Fernández and Celina Blanco (DuPont Asturias) for providing the Nomex sample. Financial support from CICYT (Project 1FD1997-1915) is gratefully acknowledged. We also acknowledge a predoctoral fellowship from the Spanish Ministry of Education awarded to S.V.-R.

\section{References}

(1) Yang, H. H. Aromatic High Strength Fibers; John Wiley \& Sons: New York, 1989.

(2) Pilato, L. A.; Michno, M. J. Advanced Composite Materials; Springer-Verlag: Berlin, 1994.

(3) Freeman, J. J.; Gimblett, F. G. R.; Hayes, R. A.; Amin, Z. M.; Sing, K. S. W. in Characterization of Porous Solids II; Rodriguez-Reinoso F., Rouquerol J., Sing K. S. W., Eds.; Elsevier: Amsterdam, 1991, p. 319.

(4) Freeman, J. J.; Tomlison, J. B.; Sing, K. S. W.; Theocaris, C. R. Carbon 1993, 31, 865.

(5) Freeman, J. J.; Tomlison, J. B.; Sing, K. S. W.; Theocaris, C. R. Carbon 1995, 33, 795.

(6) Krasnov, Y. P.; Savikov, V. M.; Sokolov, L. B.; Logunova, V. I.; Belyarov, V. K.; Polyakova, T. A. Polym. Sci. USSR 1966, 8, 413.

(7) Kalashnik, A. T.; Panikarova, N. P.; Dovbii, Y. V.; Kozhina, G. V.; Kalmykova, V. D.; Papkov, S. P. Vysokomol. 1977, 12, 2747.

(8) Khanna, Y. P.; Pearce, E. M.; Smith, J. S; Burkitt, D. T.; Njuguna, H.; Hinderlang, D. M.; Forman, B. D. J. Polym. Sci., Polym. Chem. 1981, 19, 2817. 
(9) Brown, J. R.; Power, A. J. Polym. Degrad. Stabil. 1982, 4, 379.

(10) Schulten, H. R.; Plage, B.; Ohtani, H.; Tsuge, S. Makrom. Chem. 1987, 155, 1.

(11) Carroccio, S.; Puglisi, C.; Montaudo, G. Macromol. Chem. Phys. 1999, 200, 2345.

(12) Tomikuza, I.; Isoda, Y.; Amamiya, A. Tanso 1981, 106, 93.

(13) Mosquera, M. E. G.; Jamond, M.; Martínez-Alonso, A.; Tascon, J. M. D. Chem. Mater. 1994, 6, 1918.

(14) Yoon, S.H.; Kim, B.C.; Korai, I..; Mochida I. 22 Biennial Conference on Carbon. Extended Abstracts and Program; San Diego, CA, 1995, pp. 218-219.

(15) Blazsó, M. J. Anal Appl. Pyrolysis 1995, 35, 221.

(16) Mcneill, I. C.; Ahmed, S.; Memetea, L. Polym. Degrad. Stabil. 1995, 47, 423.

(17) Setnescu, R.; Jipa, S.; Stenescu, T; Kappel, W.; Kobayashi, S.; Osawa Z. Carbon 1999, $37,1$.

(18) Dubois M.; Naji, A.; Buisson, J. P; Humbert, B.; Grivei, E.; Billaud, D. Carbon 2000, $38,1411$.

(19) Scarlete, M.; Butler, I.S.; Harrod, J.F. Chem. Mater. 1995, 7, 1214.

(20) Mokhtari, M.; Park, H.S.; Roesky, H.W.; Johnson, S.E.; Bolse, W.; Conrad, J.; Plass, W. Chem. Eur. J. 1996, 2, 1269.

(21) Hamilton, K.E.; Letts, S.A.; Buckley, S.R.; Fearon, E.M.; Wilemsky, G.; Cook, R.C.; Schroen-Carey, D. Fusion Technol. 1997, 31, 391.

(22) Göschel, U.; Walter, H. Langmuir 2000, 16, 2887.

(23) Magonov, S. N.; Whangbo, M.-H. Surface Analysis with STM and SEM; VCH: Weinheim, 1996.

(24) Magonov, S. N.; Reneker, D. H. Annu. Rev. Mater. Sci. 1997, 27, 175

(25) Bottomley, L. A. Anal. Chem. 1998, 70, 425R.

(26) Jandt, K. D. Mater. Sci. Eng. R 1998, 21, 221. 
(27) Lillehei, P. T.; Bottomley, L. A. Anal. Chem. 2000, 72, 189R.

(28) Hamilton, L. E.; Gatewood, B. M.; Sherwood, P. M. A. Text. Chem. Color. 1994, 26, 39.

(29) Zhong, Q.; Inniss, D.; Kjoller, K., Elings, V. B. Surf. Sci. 1993, 290, L688.

(30) Tamayo, J.; García, R. Langmuir 1996, 12, 4430.

(31) Paredes, J. I.; Martínez-Alonso, A.; Tascón, J. M. D. J. Mater. Chem. 2000, 10, 1585.

(32) Magonov, S. N.; Cleveland, J.; Elings, V.; Denley, D.; Whangbo, M.-H. Surf. Sci. 1997, 389, 201.

(33) Brügel, W. An Introduction to Infrared Spectroscopy; John Wiley \& Sons: New York, 1962.

(34) Nysten, B.; Roux, J.-C.; Flandrois, S.; Daulan, C.; Saadaoui, H. Phys. Rev. B 1993, $48,12527$.

(35) Blanco López, M. C.; Martínez-Alonso, A.; Tascón, J. M. D. Microporous Mesoporous Mat. 2000, 34, 171. 